likely consequences of such genetic material becoming more widely available to society are issues which are highly relevant. The contributors to the book come from a wide-ranging spectrum of interests - medical, legal, sociological, patient and workforce, and their papers, read consecutively, present a thoughtful and broad-based perspective of the problems that society will have to confront more and more in the days ahead. As huge sums are spent on trying to unravel the mysteries of the human genome, anxiety is beginning to surface on the question of how far individual genetic information should be kept completely confidential and how far it should be made available, for example as a result of medical examination for life-insurance, employment and pension schemes.

In his introduction, MF Niermeijer, points out that 'errors in specific hereditary traits (genes) are present in one per cent of newborns. They are often transmitted according to a predictable hereditary pattern. This is now known to be the case for about 4,000 genetic disorders'. However, genetic counselling could not prevent the birth of all 'defective children'. In Holland, it is thought that out of about 9,000 children born annually with congenital and/or hereditary defects, only 500-800 births would be detected as a consequence of risk limitation following genetic counselling - an 'important but modest preventive effect... . The majority of these defects are caused by an unpredictable error in the formation of the sex cells, a combination of genetic factors from two healthy parents, a disturbance during early pregnancy, or complications during or just after delivery. Thus, there is no basis for the belief that the application of modern technology might lead to a society without handicapped people. What is important is that those parents who may be at higher risk are informed in time about the risks and the possibilities of prevention.'

These are very important considerations to bear in mind when assessing the impact of such information for society as a whole. For individuals who can be identified as likely or certain developers of chronic, disabling and terminal diseases, the revelation of this could have deeply negative effects, both psychologically and for the purposes of insurance and employment. At present, the text tells us, insurers pool their risks and adjust their premiums accordingly, though they may make adjustments to take account of medical data available and an individual's life-style, for example whether he or she drinks or smokes.

Insurers would therefore be keen to have available any extra and more accurate genetic data to help evaluate the particular insurability or employability of an individual and thus the chance to offload individuals with a known high risk. How far the law or practice should prevent this happening remains debatable and there was no absolute consensus from the contributors. The competing interests of different parties will have to be weighed in the balance very carefully, and particular care given to ensuring that if genetic information is made available i) it is very carefully interpreted, and ii) it may not be used in a manner that creates two classes of individuals, those regarded as genetically 'fit' and 'unfit'.

DIANA BRAHAMS Barrister,

15 Old Square, Lincoln's Inn, London WC2A 3UH

\section{Talking and Listening to Patients - A Modern Approach}

\begin{abstract}
Charles Fletcher and Paul Freeling, 68 pages, London, $£ 2.50$, Nuffield Provincial Hospitals trust, 1988
\end{abstract}

In many ways, this is a very useful little book. It is deliberately kept short, to be a handbook for students in learning to deal comfortably with patients, both in listening to them and talking to them, and it emphasises time and again that listening to patients is a large part of the art of communicating with them.

There are, for instance, excellent examples of how this may best be achieved. There is the suggestion that patients should be asked to repeat back to doctors what they have just been told, a good way of discovering whether the patient has understood, and of finding out if there are other concerns as yet unexpressed. The doctor is encouraged to sit down with the patient rather than stand, and bad manners are roundly, and rudely, condemned.

But there are problems. Whilst the authors advocate providing patients with far more information than has hitherto been the norm, when they come to discussing what to tell terminal patients, a section of the book which is sensitively written, they nevertheless justify a certain amount of disinformation. They do this by arguing that 'students must realise that there are no rules except that hope must never be extinguished', (page 40). They cite a distinguished source, one T B Brewin, but whoever they cite, their assertion needs careful analysis. For it may be appropriate, though painful for the doctor, to extinguish hope of a long life when a patient is near death.

The reasons are many. One is that the hope may be a defence against acceptance; it therefore requires careful handling to make that sort of decision, where a patient is indicating that she or he does not wish to know. But, more importantly and more frequently, there are those who do wish to know, who do want to know, literally, that their case is hopeless, so that they may make arrangements for their loved ones and set their affairs in order. It is precisely because hope is no longer a reality that many of those terminally ill come to terms with their final arrangements, as well as sometimes fulfilling some longheld ambition.

It was surprising to read this in a book which also makes it clear that patients families should not be told too much, so that they are not in that terrible situation of knowing more than the principal protagonist, the patient. But there is an underlying instruction to be kind and gentle in this volume, which is occasionally not sufficiently toughened with an instruction to face the worst, the most hopeless, of prognoses. That apart, this is a book that every medical student should receive free at the beginning of training, and be tested on at frequent intervals. For the message, the necessity of learning to communicate with patients - is simple, and one would have thought glaringly obvious, but sadly far from frequently observed in practice.

JULIA NEUBERGER

Visiting Fellow, King's Fund Institute and Chairman, Patients Association

\section{Principles and Practice of Forensic Psychiatry}

Edited by Robert Bluglass and Paul Bowden, 1584 pages, Edinburgh, $£ 150.00$, Churchill Livingstone, 1990

This book is, as claimed by its foreword, undoubtedly a landmark in 
the development of forensic psychiatry and it will certainly come to be seen as the standard reference text of the subspecialty in the United Kingdom. It is not, however, any more than a 'curate's egg' in regard to its coverage of ethical matters. Such patchiness is to be greatly regretted, given the special and acutely focused ethical dilemmas which run throughout the practice of clinical and academic forensic psychiatry. All of psychiatric practice is distinguished from general medical practice by virtue of the pathology with which it deals, often forming the basis of the deprivation of civil liberties. But this link is essentially inherent to forensic psychiatry, and the additional dimension of interfaces with the criminal justice and penal systems emphasises the essential and constant need for all practitioners to indulge in an ethico-legal critique of their work.

The book's ethical 'curate's egg' character is represented, and probably determined by, its multi-expert author format. There are some excellent ethical deliberations by one of its editors (Bowden) concerning the provision, character and legal definition of expert reports and evidence to the courts, and this reflects his obvious ethical concerns which are demonstrated through his opening of Part III (Psychiatry and the Criminal Justice System) immediately with a definition of ethics. He well describes his own position with regard to 'the ethical issues raised in writing a report, including ... partiality, confidentiality, and the way in which potentially incriminating information may be dealt with' (page 183). Bowden's approach tends towards a 'narrow' definition of mental disorder and the avoidance of 'psychiatric speculation', alongside a clear analysis of the appropriate boundaries between psychiatric and legal concepts and functions. Kenny (an academic philosopher) is also well quoted further in relation to the definition of expertise ('there is more than usual difficulty in psychiatry in deciding when men of science are testifying within their science and when they are going beyond it').

However, even Bowden's own chapters fall short of a comprehensive ethical analysis, reflecting only a combination of great ethical concern with his own ethical solutions to dilemmas. Hence, for example, he clearly determines that the expert must not be aligned with the side which calls him, but fails then to address the very real ethical problem of the need for counsel to have access to a (partial) critique of the evidence of the other side in order knowledgeably to crossexamine, thus requiring the expert to be both an 'independent witness' and a 'partisan adviser'.

Fenwick (definitions of 'layers' of consciousness, in a chapter on medical and legal automatisms), Grounds (on seclusion, $A v$ United Kingdom [1980] European Convention on Human Rights and, minimally, with reference to ethical issues in 'psychiatric probation orders') and Bowden again (chapter on European Convention on Human Rights) also provide specific and overt ethical foci. There are, however, huge ethical gaps in this tome, which may either reflect lack of space (seemingly unlikely) or (more worryingly) lack of substantial ethical concern on the part of many of the authors. Hence there is only scant reference to the ethical implications of the unreliability of determining dangerousness (especially with reference to legal 'restriction orders') and almost total omission of ethical issues relating to other major aspects of the practice of forensic psychiatry. For example, there is nothing concerning the ethical aspects of combining therapy and security (Hamilton on Special Hospitals, Snowden on Regional Secure Units and Forensic Services in England and Wales) and only four column inches on the ethics of prison medical practice (only one of which addresses 'consent to treatment'). Indeed in the Special Hospitals chapter Hamilton seems surprised that 'the Mental Health Act Commission visits Special Hospitals with the notion that it (has) the duty "to find out what is wrong"'.

Even where there is a chapter substantially devoted to 'institutionalised ethics' (Sir John Walton, The General Medical Council of the United Kingdom on Professional Conduct), this is written without even specific reference to forensic psychiatric applications. Hence, again, only a Bowden chapter makes reference to the special issues of confidentiality which arise at the interface of psychiatry and the criminal justice and penal systems.

Ethics is best addressed to clinicians when woven into each and every individual aspect of practice and services, such that a multi-author reference book should provide an ideal form. This book is too patchy to succeed in that regard, and the literature therefore still lacks any good comprehensive treatment of ethical forensic psychiatry. Forensic psychiatry is appropriately defined and limited by its boundaries with non- medical systems and modes of thought. This 'curate's egg' does little towards a comprehensive review of such boundaries.

DR NIGEL EASTMAN

Senior Lecturer in Forensic Psychiatry, St George's Hospital Medical School, Cranmer Terrace, Tooting, London SW17 ORE

\section{The Meaning of AIDS: Implications for Medical Science, Clinical Practice, and Public Health Policy}

Edited by Eric J Juengst and Barbara $A$ Koenig, $x x+198$ pages, New York, $£ 30.95$, Praegar, 1989

The ethical issues raised by AIDS are manifold and this book attempts to discuss them on a wide-ranging basis. Its contents arise from the papers givem at a 1986 meeting on AIDS and the Medical Humanities, held in Sam Francisco. The book falls into three sections: interpreting our knowledge of AIDS; the clinical experience of AIDS, and AIDS and the public health.

The first section, on interpreting knowledge of AIDS, raises some interesting issues which arise out of the construction of AIDS as a disease. As the editors note in their introduction, the discovery of the AIDS virus and the history of attempts to differentiate various stages of HIV infection provide an important case study for those interested in the complex dynamics of biomedical explanation. The international disputes over the naming of the AIDS virus and the early association of AIDS with promiscuity also draw attention to the role of cultural and political influences in determining medical definitions. Unfortunately few of the papers in this section take these ideas any further and it has been left to other authors, most notably Paula Treichler, to illuminate the processes surrounding AIDS as a cultural construct.

Section two deals more straightforwardly with the ethical issues raised in clinical practice. It gives an historical survey of doctors' responsibilities in epidemics; presents the results of a survey of young hospital doctors' reactions to AIDS patients in San Francisco; outlines the possible conflicts between patients and families 